Research Article

\title{
Temporal and Spatial Change Monitoring of Drought Grade Based on ERA5 Analysis Data and BFAST Method in the Belt and Road Area during 1989-2017
}

\author{
Changdi Xue $\mathbb{D}^{1},{ }^{1}$ Hua $W u\left(\mathbb{D},,^{1,2,3}\right.$ and Xiaoguang Jiang ${ }^{1,4}$ \\ ${ }^{1}$ University of Chinese Academy of Sciences, Beijing 100049, China \\ ${ }^{2}$ State Key Laboratory of Resources and Environment Information System, \\ Institute of Geographic Sciences and Natural Resources Research, Chinese Academy of Sciences, Beijing 100101, China \\ ${ }^{3}$ Jiangsu Center for Collaborative Innovation in Geographical Information Resource Development and Application, \\ Nanjing 210023, China \\ ${ }^{4}$ Key Laboratory of Quantitative Remote Sensing Information Technology, Academy of Opto-Electronics, \\ Chinese Academy of Sciences, Beijing 100094, China
}

Correspondence should be addressed to Hua Wu; wuhua@igsnrr.ac.cn

Received 28 February 2019; Accepted 3 October 2019; Published 16 November 2019

Guest Editor: Jayant K. Routray

Copyright (C) 2019 Changdi Xue et al. This is an open access article distributed under the Creative Commons Attribution License, which permits unrestricted use, distribution, and reproduction in any medium, provided the original work is properly cited.

Drought is a worldwide natural disaster with a wide range of influences and a long duration, which has a huge impact on the agricultural production activities and social economy of local residents. The Belt and Road Initiative has always received much attention due to its special geographical location and great potential for economic development. At the same time, the Belt and Road region is also deeply affected by drought, especially in some countries and regions, where the agricultural infrastructure is weak and the ecological environment is fragile. How to effectively monitor and evaluate drought has become an urgent problem to be solved. In this study, the ERA5 atmospheric reanalysis data were used, and the self-calibrating Palmer Drought Severity Index was combined with Breaks for Additive Seasonal and Trend (BFAST) to study the temporal and spatial distribution of the 1989-2017 monthly scale of drought in different climate regions of the Belt and Road region. The results show that the overall change trend of arid area shows a change of "up-down-up-down." The winter drought area is larger than the summer drought area, and the drought center gradually moves from the Southeast Asia region in winter to the West-Central Asia region in summer. In the past five years, the drought area decreased gradually at the rate of approximately 0.38 million $\mathrm{km}^{2}$ per year.

\section{Introduction}

Drought is an unusually dry incident over a period, causing water shortages for long enough to cause severe hydrological imbalances in the affected areas [1]. The imbalance of water budget is caused by the combined effects of climatic conditions, underlying surface, and human activities. Compared with floods, hurricanes, and other disasters, the process of drought is much slower $[2,3]$. It usually takes several months or even several seasons [4]. It is easy to be ignored. Once it becomes a disaster, it has a large scope and lasts for a long time [5]. In the United States, drought causes an average of $\$ 6-8$ billion in annual losses, but in 1988 , it reached $\$ 40$ billion [6]. Drought-related disasters in the 1980s caused more than half a million deaths in Africa [7].

Since the beginning of the last century, more and more researchers have realized the importance of drought monitoring, but due to technical limitations, most of them use weather station data to monitor and forecast drought [8-11]. With the development of remote sensing technology, the use of satellites to acquire long-term and large-scale meteorological data for monitoring environmental disasters has gradually become a mainstream method [12-14], such as the TRMM satellite. Its spatial resolution is $0.25^{\circ}$, and the time resolution is 1 hour, covering the area between $50^{\circ} \mathrm{N}$ and $50^{\circ} \mathrm{S}$, spanning the period 1998 to 2018 . It is a very powerful 
source of meteorological data [15-18]. In recent years, reanalysis data have widely been used in climate simulation prediction [19, 20]. Several researchers use ERA-Interim reanalysis dataset from the European Centre for MediumRange Weather Forecasts (ECMWF) and a refined version of a previously developed Lagrangian methodology to compile a global climatology of stratosphere-troposphere exchange (STE) from 1979 to 2011 [21]. Several researchers examined low-frequency variability and trends in temperature from 1979 to 2012, and near-surface behaviour of the ERA-Interim reanalysis is reviewed [22]. Several researchers model the climatic mass balance of the ice cap for the period September 2000 to August 2009 on ERA-Interim reanalysis [23].

Since the beginning of the 20th century, as the complexity of drought formation and the breadth of its effects have deepened, the researchers constructed a series of drought assessment indicators using easily available observational elements such as precipitation, temperature, evaporation, runoff, soil moisture, and remote sensing [24-26]. These assessment indicators study and depict drought from the perspective of meteorology, hydrology, agriculture, and other disciplines and begin to try to consider drought from a multifactor perspective. Representative drought indicators are as follows: Standardized Precipitation Index (SPI) [27], the Rainfall Deciles (RD) [28] reflect the water deficit of atmospheric process, and Computed Soil Moisture (CSM) [29] and Soil Moisture Deficit Index (SMDI) [30] reflect the water deficit of Soil process, and Total Water Deficit (S) [31] reflects the water deficit of the surface process. At the same time, there are a series of standardized comprehensive indexes, such as Normalized Difference Vegetation Index (NDVI) [32], Standardized Precipitation Evapotranspiration Index (SPEI) [33], Palmer Drought Severity Index (PDSI) [34], and Palmer Hydrological Drought Index (PHDI) [34]. On the one hand, these indicators reflect the water deficit in the atmosphere, soil, or surface, and on the other hand, their regional adaptability and transplantability are significantly enhanced, which can be applied to most parts of the world [35]. In view of these drought indexes, combining with modern climate statistical diagnosis technology, separating precipitation change trend from climate series can effectively monitor precipitation change and then monitor drought [36]. In addition to the traditional methods such as moving average [37], cumulative anomaly percentage [38], and linear tendency estimation [39], some researchers have also introduced new methods such as spline function to better reflect its real trend [40]. In addition, the significance test of the change trend is also emphasized. More commonly used are the MannKendall detection [41], Yamamoto method [42], and so on.

Due to the large population and economic proportion of the Belt and Road, there are many cities with unbalanced cultural and economic development. Meteorological disasters, especially droughts, often have serious consequences for agricultural production in different countries. The region has a weak national agricultural infrastructure and relatively little investment in disaster prevention, mitigation, and relief, as the limitations of economic development lead to very heavy losses in the event of an accident [43]. Therefore, it is necessary to understand the distribution and variation of drought in the Belt and Road region. Due to the small coverage area of meteorological stations, some stations lack data, and the time series is not continuous, while the coverage area of satellite data is wide, but the time series is short for drought research. This paper calculates the self-calibrating Palmer Drought Severity Index (scPDSI) using ERA5 atmospheric reanalysis data and analyzes the distribution and change of drought in the Belt and Road region from 1989 to 2017 through Breaks for Additive Seasonal and Trend (BFAST) analysis [25, 44, 45]. We hope to contribute effectively to drought reduction by providing analysis of the drought situation in the Belt and Road region.

\section{Materials and Methods}

2.1. Area. The Belt and Road stretches across Asia, Europe, and Africa, from $0^{\circ}$ North to $60^{\circ}$ North and from $10^{\circ} \mathrm{West}$ to $110^{\circ}$ East, and includes 70 countries and cities in the maritime regions, including the Western Pacific, Indian Ocean, Mediterranean Sea, Red Sea, and land. In the past research, most researchers use the state or national boundaries to study the distribution and change of drought in different regions. It is well known that the same geographical region usually contains different climatic types, and it may be inaccurate to compare drought under different climatic types in one region. In order to study the variation of drought under different climate regions better, according to the Wladimir Köppen climate zone classification [46], we divided the whole region into equatorial, arid, warm, snow, and polar. The climate classification system was proposed by a German climatologist Wladimir Köppen. Climate is classified according to temperature and precipitation, and according to the distribution of natural vegetation. First, the world's climate is divided into five climatic zones and expressed in majuscule terms: the tropical zone (equatorial), the arid zone (arid), the temperate zone (warm), the cold temperate zone (snow), and the polar climatic zone (polar). In the five climatic zones, except dry climate, all of them are bounded by isotherms. Precipitation and temperature were then used as secondary and tertiary classification indicators to divide the world into 31 climatic regions. For convenience and accuracy, this study used only Wladimir Köppen's classification of the world's five basic climate zones. The Belt and Road region is divided into five regions: namely, the tropical zone (equatorial), the arid zone (arid), the temperate zone (warm), the cold temperate zone (snow), and the polar zone (polar), see Figure 1 for classification of search area.

2.2. Data. The atmospheric reanalysis data, which have the advantages of long time series and high resolution, can be used not only for the diagnostic analysis of weather and climate but also for the assimilation of a large number of satellite data and routine data such as ground and upper air data. It can also be used in meteorological boundary fields for weather and climate models. ERA5 is a new climate reanalysis dataset (5th generation) from ECMWF (the 


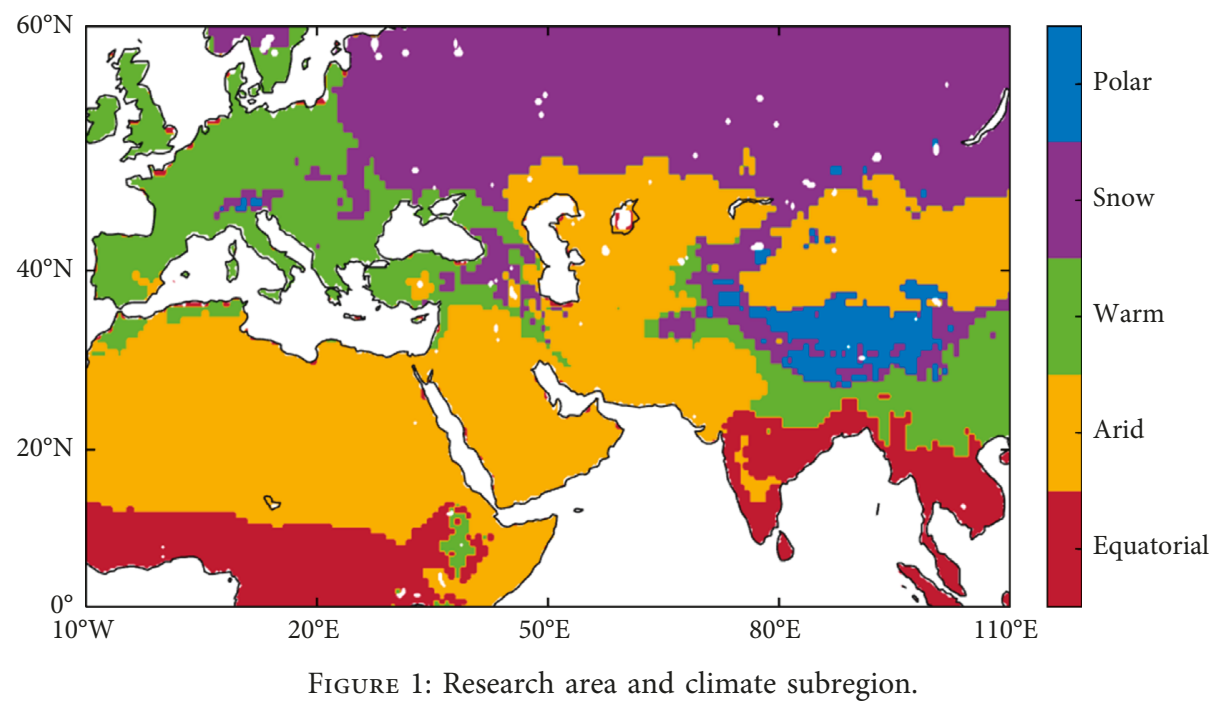

European Centre for Medium-Range Weather Forecasts) [21]. The resolution was increased from $79 \mathrm{~km}$ to $31 \mathrm{~km}$, the time resolution from 3 hours to 1 hour, the number of vertical layers from 60 to 137, and the time span from 1950 to the present (data for some years are still being processed). Based on the availability of the data, we selected atmospheric reanalysis data from 1989 to 2017, with the main variables being total precipitation and near-surface temperature. At the same time, in order to calculate the scPDSI, we used available water-holding capacity (AWC) from SoilGrids dataset [47-49], which was developed by random forest and gradient-enhanced tree algorithms combined with global soil profile data compilation (approximately 1,30,000 sites) and borehole data (approximately 1.6 million sites).

Daily atmospheric reanalysis data in the Belt and Road area from 1989 to 2017, which were collected from ECMWF, are used in this study. According to the world map of the Köppen-Geiger climate classification, we divide the study area into different climate types (available online at https:// people.eng.unimelb.edu.au/mpeel/koppen.html). The soil data were downloaded from the World Soil Information (available online at https://www.isric.org/explore/soilgrids).

The ERA5 reanalysis data and soil data used to support the findings of this study can be downloaded from the corresponding website on the Internet (https://climate. copernicus.eu/). The scPDSI data used to support the finding of this study are available from the corresponding author upon request.

\section{Method}

3.1. scPDSI. This study uses the scPDSI [26], which is a drought index based on the relationship between water supply and demand proposed by Wayne Palmer in 1965. PDSI can take into account not only the current water supply and demand situation but also the effect of dry and wet situation and its duration on the current drought situation [34]. In order to improve the transplantability and spatial comparability of PDSI, wells and other researchers proposed scPDSI that can automatically modify the local climate [26].

Firstly, scPDSI has similar variation range under different climatic conditions. This makes it a more suitable indicator for comparing the relative availability of water in different regions. Secondly, potential evapotranspiration is calculated using the physical-based Penman-Monteith parameterization, using actual vegetation cover rather than reference crops. Thirdly, the seasonal dynamics of snow cover is considered in the water balance model $[44,50]$. The scPDSI was calculated using a program developed by researchers at the University of Nebraska, Lincoln (http:// greenleaf.unl.edu/).

3.2. Breaks for Additive Seasonal and Trend. BFAST was originally used to identify vegetation disturbance using remote sensing data. Compared with other change detection methods, such as PCA, Fourier analysis, wavelet analysis, and transform vector analysis, the advantages are as follows: firstly, BFAST can analyze all time series data and consider seasonal variation effectively avoiding the error caused by seasonal segmentation. Secondly, BFAST iteratively estimates the date and number of changes in the seasonal and trend components and characterizes the changes by extracting the magnitude and direction of the changes. Thirdly, BFAST is suitable for all types of remote sensing data and can be applied to other time series data without the need to select reference cycles, set thresholds, or define change trajectories $[45,51,52]$.

The general pattern is as follows:

$$
Y_{t}=T_{t}+S_{t}+e_{t}
$$

It is widely used and can be used in meteorology, hydrology, economics, and other fields. By decomposing the data over a period of time into long-term trend components, periodic components, and the remaining components, in which the trend components are fitted using a linear model, the model is (2), and the periodic components are fitted 
using a periodic model. The model takes the form of formula (3):

$$
\begin{aligned}
& T_{t}=\alpha_{i}+\beta_{i} t \\
& S_{t}=\sum_{k=1}^{j} \alpha_{j, k} \sin \left(\frac{2 \pi k t}{f}+\delta_{j, k}\right) .
\end{aligned}
$$

Another key point is the identification of mutation points in time series. The BFAST algorithm uses the ordinary least squares (OLS) residual-based MOving SUM (MOSUM) test to determine whether there are mutation points and uses Bayesian information theory to determine the optimal number of mutation points. The position of the mutation point in the time series is estimated by the least squares.

As shown in Figure 2, the data preprocessing and scPDSI were firstly calculated based on the climate zone classification. The BFAST algorithm was then used to detect the presence of abrupt climate change points in the time series. The causes of abrupt climate change were finally analyzed. In this study, the BFAST algorithm is implemented in the R language BFAST algorithm package (http://bfast.r-forge.rproject.org/).

\section{Results}

The scPDSI from 1989 to 2017 was calculated according to the calculation method of scPDSI mentioned in 3.1, and then the drought grades of 29 years were classified by using the drought index classification method in Table 1. Figure 3 shows the distribution of the average scPDSI drought index in 1998, with extreme droughts in central Africa, southern and Central Asia, and southern Europe, in contrast to increased precipitation in northern Europe and Central Asia. The rest are slightly and moderately dry. Figure 4 shows the distribution of drought grades from January to December 1998. For Europe, there were more severe droughts in February, April, and November, mainly in southern countries and regions, including Italy, Greece, Albania, Serbia, Austria, Hungary, and the West Coast of Spain; for Asia, West Asia is the main arid region, and the drought has also affected Central Asia in some months, with Saudi Arabia, Yemen, Iraq, Pakistan, and Iran being the main affected countries. Central Asia, on the other hand, is dominated by central Russia and Kazakhstan; for Africa, it's a perennial drought, with frequent droughts in Ethiopia, Djibouti, and northern Africa, mainly in winter and spring. It has a great impact on the daily life of the local people. As a region with abundant rainfall, Southeast Asia is prone to drought, which occurs mainly in autumn and winter, especially from September to December. The intensity of the drought gradually increased. Figure 5 illustrates the intensity change trend of PDSI from 1989 to 2017 in different climate regions, and Figure 5 illustrates the change trend of drought area (scPDSI <-1) from 1989 to 2017 in different climate regions, in order to better reflect the drought change.

Figure 5(e) shows the percentage change of drought area from 1989 to 2017 . It is obvious that the drought area shows a trend of "up-down-up-down," which becomes clearer after

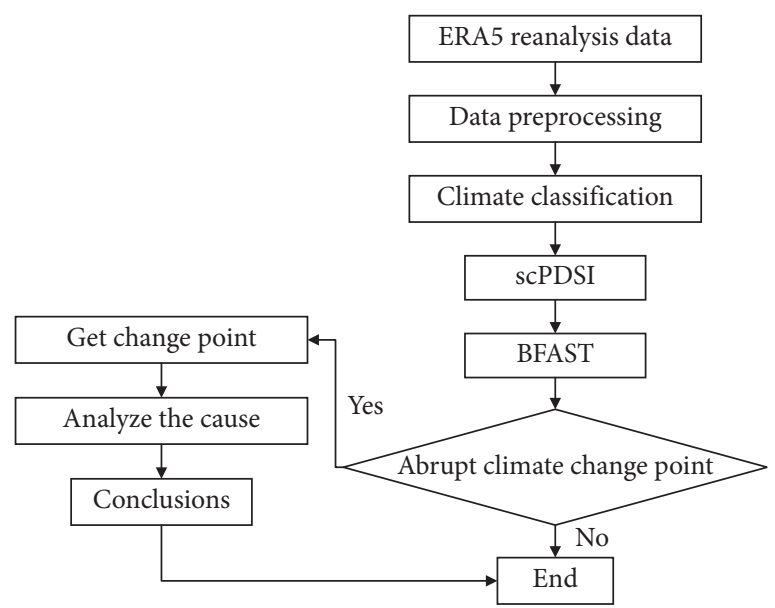

FIgURE 2: Graphical framework of methodology.

Table 1: Drought category based on the scPDSI value.

\begin{tabular}{lcc}
\hline Rank & Category & scPDSI \\
\hline 1 & No drought & $>-1.0$ \\
2 & Slight drought & $-2.0:-1.0$ \\
3 & Medium drought & $-3.0:-2.0$ \\
4 & Severe drought & $-4.0:-3.0$ \\
5 & Extreme drought & $<-4.0$ \\
\hline
\end{tabular}

BFAST algorithm decomposition. Among them, from 1989 to 1998 , the drought area percentage gradually increased from $20 \%$ to $70 \%$, which is the largest change in the past 30 years. From 1999 to the present, the trend of drought change basically accords with the change every five years. It can be seen from the periodic component that the drought area in the whole region of Belt and Road reaches the maximum in winter and spring and is lower in summer and autumn. The trend component $T_{t}$ indicates that there are four arid climate change points from 1989 to 2017 and five periods of different periods of drought. The linear fitting of the monthly area change line of the five-stage drought period was obtained, and the slopes of the five-stage trend were 0.000191, 0.0053, $-0.00513,0.0034$, and -0.00439 . Based on the ERA5 resolution, the total area of the Belt and Road is estimated to be approximately 86.80 million $\mathrm{km}^{2}$. So, the drought area decreased gradually at the rate of approximately 0.38 million $\mathrm{km}^{2}$ per year from 2012 to 2017.

\section{Discussion}

5.1. Regional Variation Patterns of Drought Levels. The tropics have plenty of rainfall, with an annual average temperature of $800 \mathrm{~mm}$ or more, mainly in central Africa, much of India, and Southeast Asia; the arid regions include northern Africa, West Central Asia, and Northwest China. The annual precipitation is low, and the underlying surface is mainly desert and mountainous; the temperate zone mainly includes most of Europe and southwest China, which is strongly influenced by the monsoon, and the precipitation is seasonal. The cold temperate zone mainly includes northern Asia, eastern Europe, and the edge of the Qinghai-Tibet 


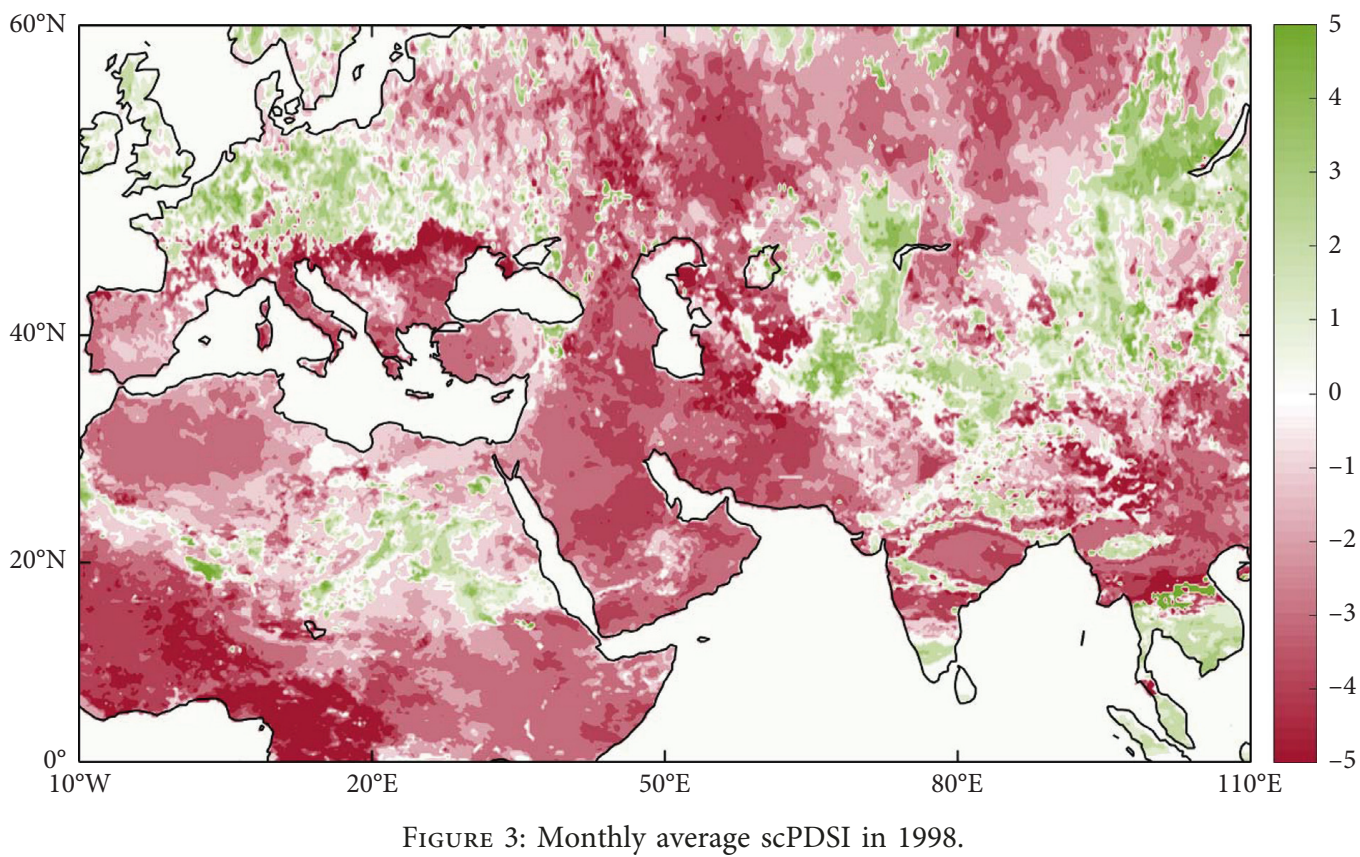

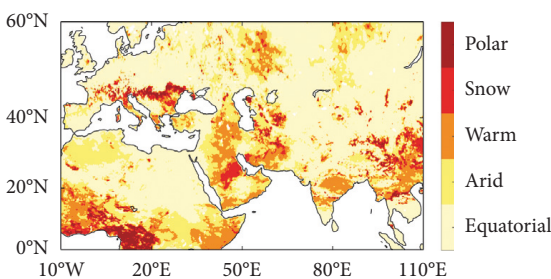

(a)

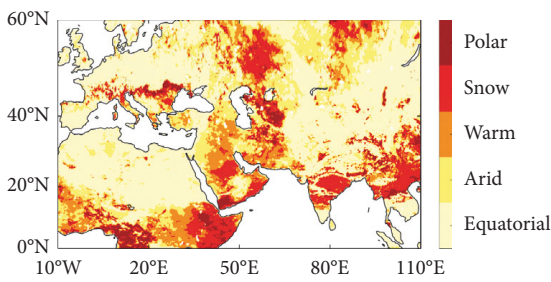

(c)

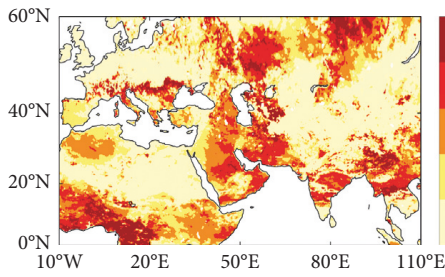

(e)

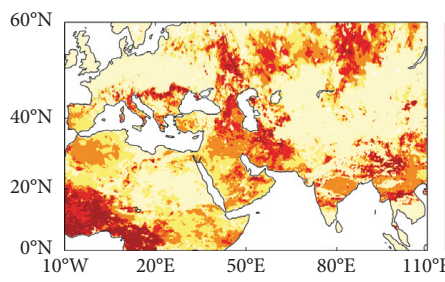

(g)

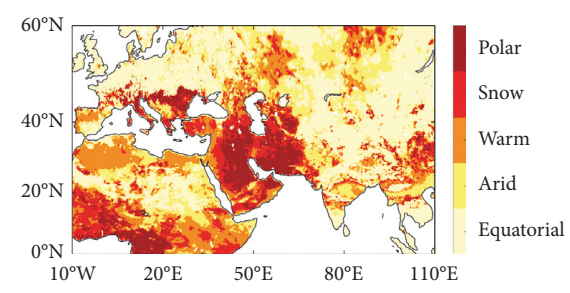

(b)

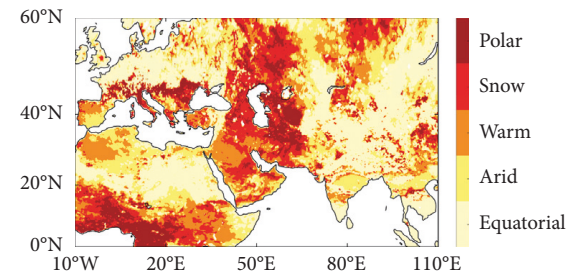

(d)

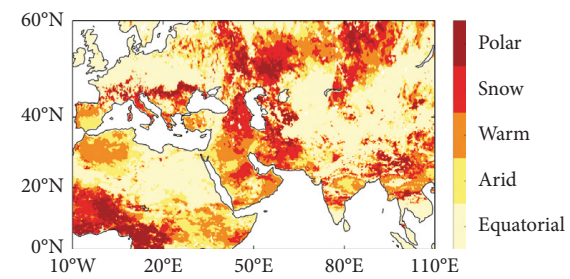

(f)

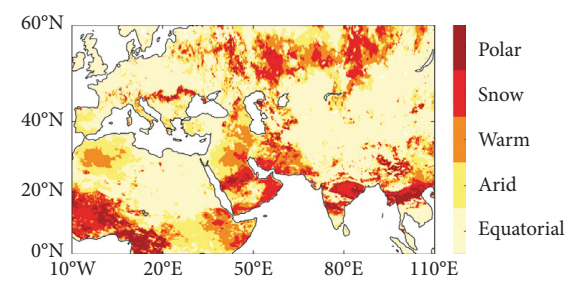

(h)

Figure 4: Continued. 


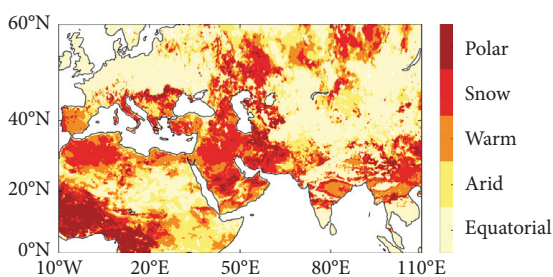

(i)

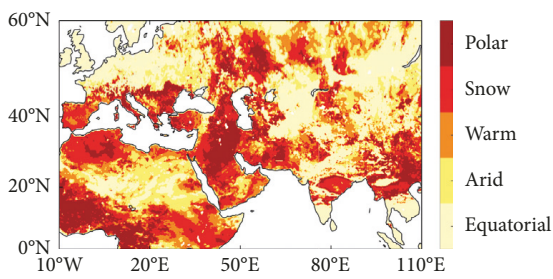

(k)

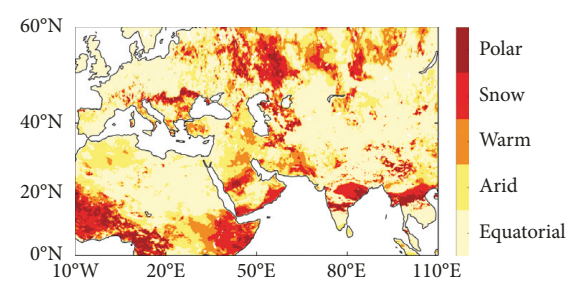

(j)

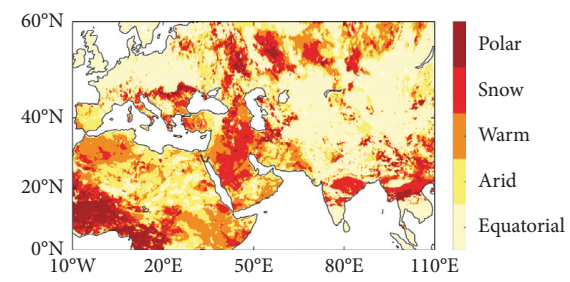

(l)

Figure 4: Spatiotemporal distribution of drought in Belt and Road area. (a) Jan. 1998. (b) Feb. 1998. (c) Mar. 1998. (d) Apr. 1998. (e) May. 1998. (f) Jun. 1998. (g) Jul. 1998. (h) Aug. 1998. (i) Sept. 1998. (j) Oct. 1998. (k) Nov. 1998. (l) Dec. 1998.

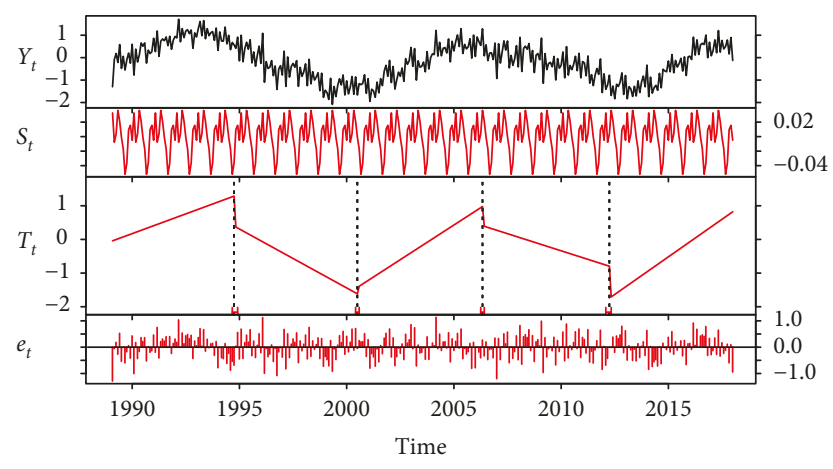

(a)

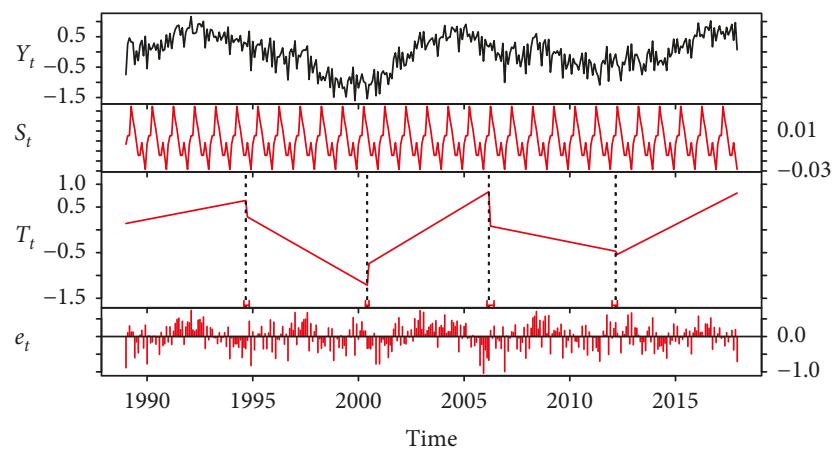

(c)

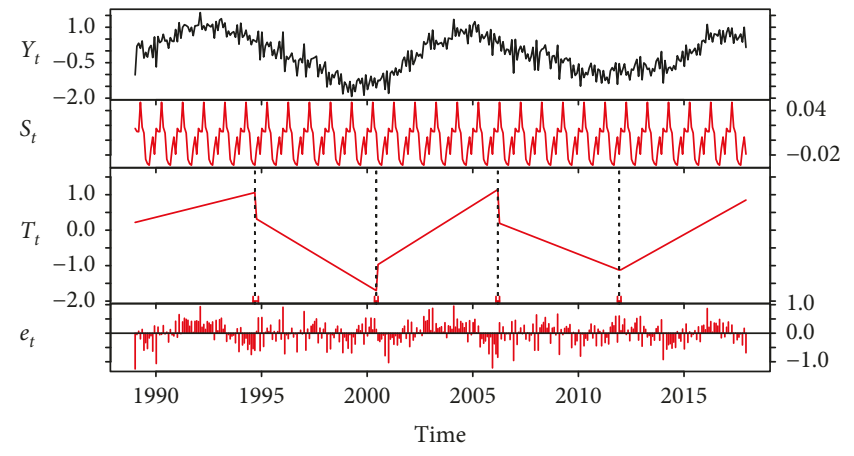

(b)

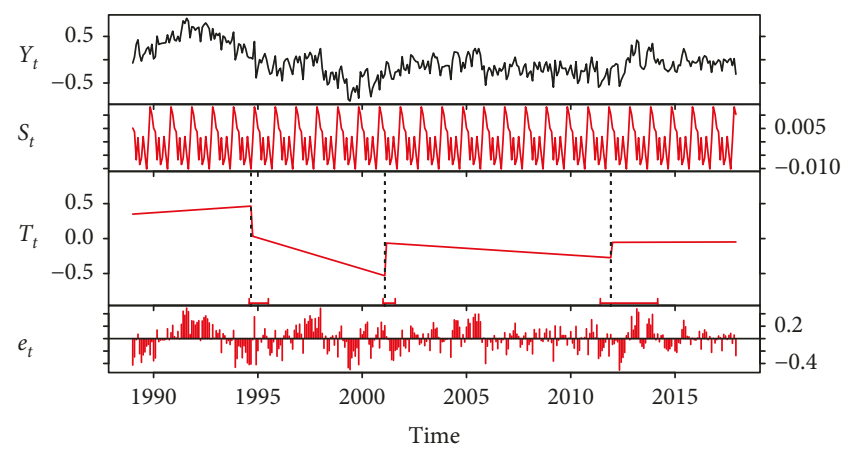

(d)

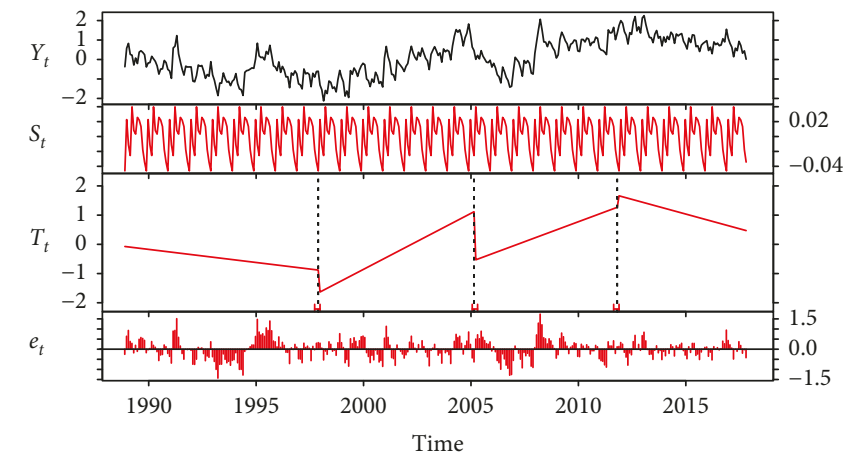

(e)

FIgUre 5: Trends of monthly scPDSI for the subregions. (a) Equatorial. (b) Arid. (c) Warm. (d) Snow. (e) Polar. 


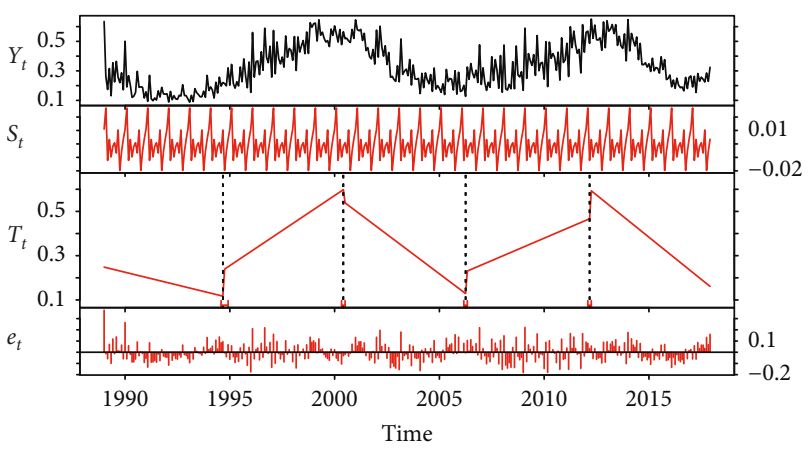

(a)

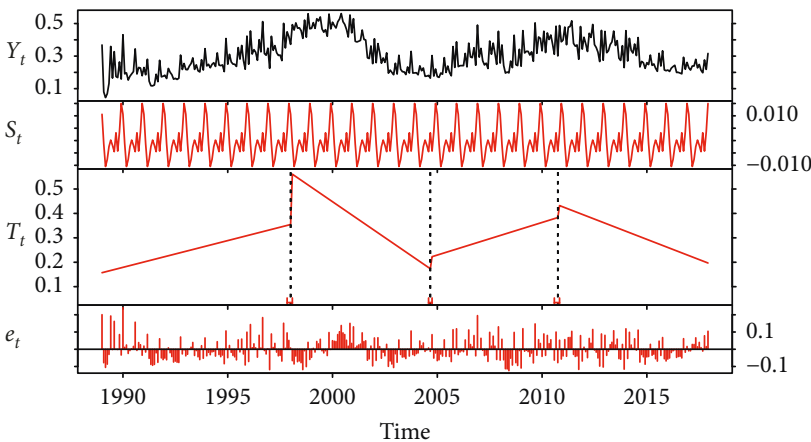

(c)

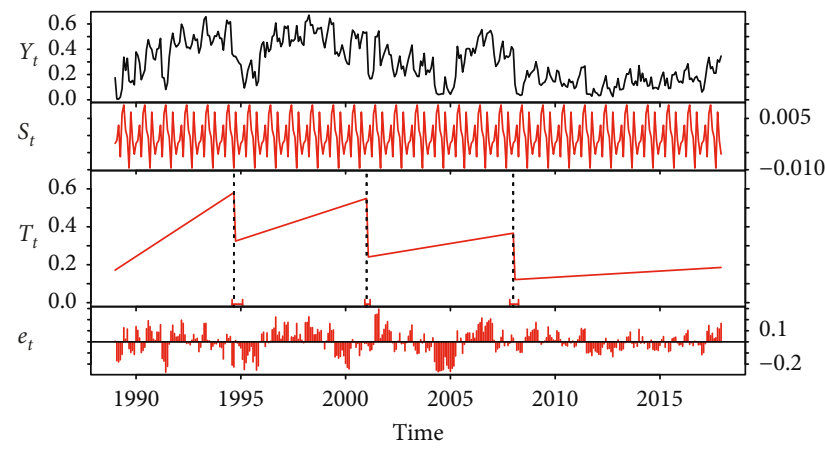

(e)

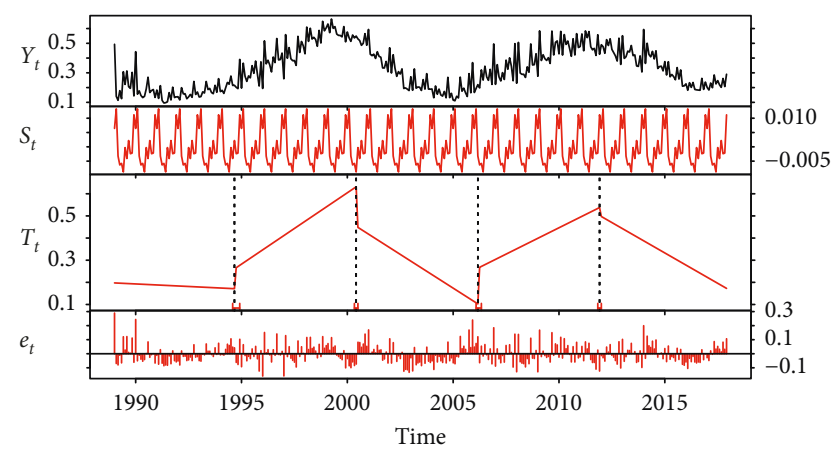

(b)

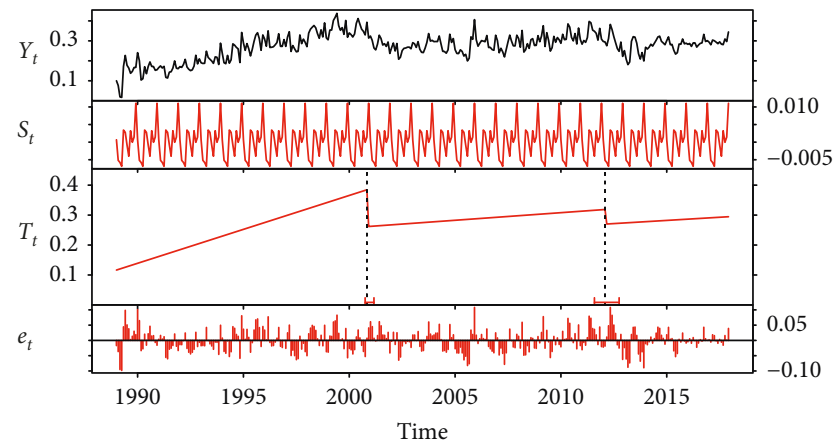

(d)

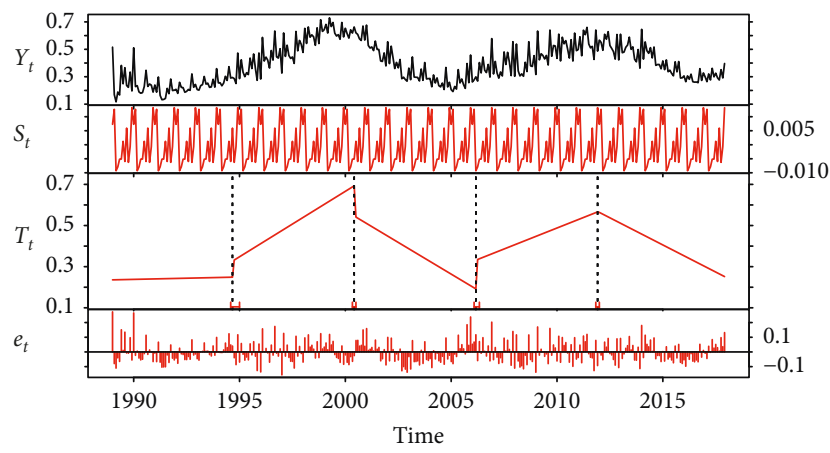

(f)

FIGURE 6: Trends of monthly average area percentage of the subregions in the Belt and Road area. (a) Equatorial. (b) Arid. (c) Warm. (d) Snow. (e) Polar. (f) Entire study area.

Plateau. The annual average temperature is relatively low, and ice and snow are the basic forms of precipitation in winter. For the tropical region (Figure 5(a)), it can be seen from the periodic component that the drought mainly occurs in autumn, and judging from the scPDSI of the monthly scale, it is a mild drought because of the mean value. So the drought is less severe than it actually is. According to the trend component, the slope of drought grade change in five periods was $0.0195,-0.0292,0.0343,-0.017$, and 0.0372 , which showed obvious cycle change. For arid climate areas (Figure 5(b)), summer and autumn are frequent periods of drought, and most areas are moderate or extreme drought; from the perspective of the trend component, the slope of drought grade change in five periods was $0.0124,-0.0297$, $0.0311,-0.0194$, and 0.0277 , and the drought degree increased between 1995 and 2000. For the temperate zone
(Figure 5(c)), the drought is serious in winter, and most of the areas are mild and moderately drought. From the trend component, the slope of the five-stage period was 0.00742 , $-0.022,0.0232,-0.00774$, and 0.0198 . The degree of drought increased between 1995 and 2000. For the cold temperate zone (Figure 5(d)), the summer drought was severe, and most of the areas were slightly arid. From the trend component, the slope of the four-stage period was 0.00168 , $-0.00743,-0.00162$, and 0.00008 , and the degree of drought tends to be stable between 2000 and 2015. For the polar climate region (Figure 5(e)), the drought is serious in spring and spring, and most areas are slightly dry. From the trend component, the slopes of the four periods were -0.00747 , $0.0319,0.0228$, and -0.0168 . The drought degree was gradually serious between 1990 and 1998 and then gradually improved from 1999 to 2005 and from 2006 to 2011, but it 
can be seen that the annual average scPDSI shows a downward trend after 2012.

\subsection{Regional Variation Patterns of Drought Areas.} Comparing the changes of the arid area of the five climate type areas with the whole study area, it is found that the entire area shows a trend of "up-down-up-down." Of these, the percentage change in the arid area of the polar climate region was the largest, increasing from $11.33 \%$ in October 1995 to $67 \%$ in April 1998. For the polar climate region (Figure 5(e)), the trend of the percentage change of arid area is divided into four stages, which are the increasing trend of drought in different degrees, but when the arid area reaches a certain degree, there will be a sharp decline. This indicates that the duration of drought in polar climate region is short, and the slope of the four segments was $0.00601,0.003$, 0.00151 , and 0.000541 , respectively. This indicates that the rate of change in the extent of drought has gradually decreased over time, especially since 2008 , the change in the area of drought has been moderate, and the tropical, arid, and temperate climatic regions basically conform to the overall trend of the change in the area of drought (Figures 6(a)-6(c)). But the variation range of adjacent months in tropical climate region is larger than that in arid climate region and temperate climate region. The proportion of arid areas in the cold temperate zone is relatively small (Figure 6(d)), ranging from 10 to 30 percent. On the one hand, because the cold temperate mainly in Russia, deep into the hinterland of the Asian continent, less precipitation. On the other hand, the cold temperate zone area is vast, but the change rate of drought area will be stable. For the cold temperate regions (Figure 6(e)), from 1989 to 2017, there were two major abrupt climate change points, the first in 2001 and the second in 2012. The slopes of the three aridity area curves were $0.00189,0.000423$, and 0.000353 . The rate of increase in arid areas is levelling off.

\section{Conclusions}

Most previous studies were confined to smaller research areas, in which case, climate differences between different regions need not to be taken into account. Although the BFAST time series analysis method may get the trend and distribution characteristics of the drought index in different periods, the selected research area in this study is large, where it is not a good way to use the BFAST method alone. In addition, considering the long study period, the scPDSI may be more suitable for the reason that it can be self-calibrated according to the local climate and comprehensively and accurately describe the drought situation. Consequently, the authors tried to introduce the Köppen-Geiger climate zone into the change monitoring of the temporal and spatial distribution of the 1989-2017 monthly scale of drought with the scPDSI and the BFAST method. The classification by climate type avoids the selective error caused by subjective judgment. The change trend of drought and the abrupt change point of climate in the whole climate region can be well captured. In addition, by comparing the drought situation in different climatic regions, the degree of drought risk under different climatic influences can also be obtained. The development trend of drought in different climatic zones would be clarified. Based on the ERA5 data, the spatial distribution and temporal and spatial variation of drought in the Belt and Road region from 1989 to 2017 were studied by using the adaptive Palmer drought model. Overall, the results of our research and analysis of the distribution of drought in the Belt and Road are as follows.

In terms of spatial distribution, the area of winter drought is larger than that of summer drought, and winter drought mainly occurs in central Africa and West Asia, as well as parts of Southeast Asia summer droughts occur mainly in Central and Western Asia, much of Southeast Asia, and northern Africa. Taking into account the year-toyear distribution, the arid regional center moves eastward from West-Central Asia as the seasons change from winter to summer. In April 1999, 72.9 percent of the Belt and Road area was dry, the highest percentage in nearly three decades. According to the classification results of different climatic regions, the change trend of the percentage of arid area in arid, tropical, and temperate climate regions is "updown-up-down." For the cold temperate zone and the polar climate zone, the trend of change increases slowly, and it is not clear whether the area of drought is likely to reduce the trend. In the past five years, the drought area decreased gradually at the rate of approximately 0.38 million $\mathrm{km}^{2}$ per year.

This study used ERA5 atmospheric reanalysis data and self-calibrating Palmer Drought Severity Index to describe the occurrence and development trends of droughts in the Belt and Road from 1989 to 2017. It has a certain reference value for revealing the spatial and temporal distribution characteristics of drought in the Belt and Road area. From the view of data, extending the time span to 50 years may be more conducive to the estimation and analysis of drought trends. From the point of view of drought assessment, further research can be carried out using multiple drought indices for comprehensive assessment. For agricultural production, the next study will take into account agricultural factors such as crop drought tolerance and agricultural production data, and further study will take into account the direct impact of drought on agricultural production.

\section{Data Availability}

The ERA5 reanalysis data and soil data used to support the findings of this study can be downloaded from the corresponding website on the Internet. The scPDSI data used to support the finding of this study are available from the corresponding author upon request.

\section{Conflicts of Interest}

The authors declare that they have no conflicts of interest.

\section{Authors' Contributions}

The authors contributed equally to this paper. 


\section{Acknowledgments}

This work was supported partly by the Strategic Priority Research Program of Chinese Academy of Sciences under grant nos. XDA20030302 and XDA19040403 and partly by the National Natural Science Foundation of China under grant no. 41871267.

\section{References}

[1] A. Dai, "Drought under global warming: a review," Wiley Interdisciplinary Reviews: Climate Change, vol. 2, no. 1, pp. 45-65, 2011.

[2] A. K. Mishra and V. P. Singh, "A review of drought concepts," Journal of Hydrology, vol. 391, no. 1-2, pp. 202-216, 2010.

[3] Z. Maosheng and S. W. Running, "Drought-induced reduction in global terrestrial net primary production from 2000 through 2009," Science, vol. 329, no. 5994, pp. 940-943, 2010.

[4] J. G. Charney, "Dynamics of deserts and drought in the Sahel," Quarterly Journal of the Royal Meteorological Society, vol. 101, no. 428, pp. 193-202, 2010.

[5] A. Dai, "Increasing drought under global warming in observations and models," Nature Climate Change, vol. 3, no. 1, pp. 52-58, 2013.

[6] J. Newton, "Federal legislation for disaster mitigation: a comparative assessment between Canada and the United States," Earthquake and Atmospheric Hazards, vol. 16, no. 2-3, pp. 219-241, 1997.

[7] G. Kallis, "Droughts," Annual Review of Environment and Resources, vol. 33, no. 1, pp. 85-118, 2008.

[8] M. J. Salerno, "Assessing the predictability of weekly drought improvement using nebraska's automated weather data network," ProQuest dissertations publishing, Creighton University, Omaha, NE, USA, 2015.

[9] K. L. Webster, J. W. Mclaughlin, Y. Kim, M. S. Packalen, and C. S. Li, "Modelling carbon dynamics and response to environmental change along a boreal fen nutrient gradient," Ecological Modelling, vol. 248, no. 1751, pp. 148-164, 2013.

[10] J. Fan, M. Zhang, G. Cao, X. Zhang, and J. Wu, "Integration of drought monitoring with remote sensing into the global drought information system," Proceedings of SPIE-The International Society for Optical Engineering, vol. 8531, no. 8, pp. 468-472, 2012.

[11] H. Ezzine, A. Bouziane, and D. Ouazar, "Seasonal comparisons of meteorological and agricultural drought indices in Morocco using open short time-series data," International Journal of Applied Earth Observations \& Geoinformation, vol. 26, no. 1, pp. 36-48, 2014.

[12] Z. Tian, B. Nijssen, G. J. Huffman, and D. P. Lettenmaier, "Evaluation of real-time satellite precipitation data for global drought monitoring," Journal of Hydrometeorology, vol. 15, no. 4, pp. 1651-1660, 2014.

[13] H. Cui, J. Zhang, and F. Yao, "Combination of multi-sensor remote sensing data for drought monitoring over Southwest China," International Journal of Applied Earth Observations \& Geoinformation, vol. 35, pp. 270-283, 2015.

[14] S.-B. Duan, Z.-L. Li, B.-H. Tang, H. Wu, and R. Tang, "Generation of a time-consistent land surface temperature product from MODIS data," Remote Sensing of Environment, vol. 140, pp. 339-349, 2014.

[15] A. Yaduvanshi, P. K. Srivastava, and A. C. Pandey, "Integrating TRMM and MODIS satellite with socio-economic vulnerability for monitoring drought risk over a tropical region of India," Physics and Chemistry of the Earth, Parts A/ B/C, vol. 83-84, pp. 14-27, 2015.

[16] S. Park, J. Im, J. Eunna, and R. Jinyoung, "Peer review report 1 on "drought assessment and monitoring through blending of multi-sensor indices using machine learning approaches for different climate regions"," Agricultural and Forest Meteorology, vol. 217, p. 50, 2016.

[17] X. Cao, Y. Feng, and J. Wang, "An improvement of the TsNDVI space drought monitoring method and its applications in the Mongolian plateau with MODIS, 2000-2012," Arabian Journal of Geosciences, vol. 9, no. 6, p. 433, 2016.

[18] W. Yao, Z. Xu, Z. Bing, and L. Qi, "Monitoring the meteorological drought in the middle reaches of Heihe River basin based on TRMM precipitation data," in Proceedings of the 2016 Geoscience \& Remote Sensing Symposium, Beijing, China, July 2016.

[19] S. Chen, T. Y. Gan, X. Tan, D. Shao, and J. Zhu, "Assessment of CFSR, ERA-Interim, JRA-55, MERRA-2, NCEP-2 reanalysis data for drought analysis over China," Climate Dynamics, vol. 53, no. 1-2, pp. 737-757, 2019.

[20] Z. Wang, K. Guan, J. Sheffield, and E. F. Wood, "Depiction of drought over sub-Saharan Africa using reanalyses precipitation datasets: depiction of drought using reanalyses," Journal of Geophysical Research Atmospheres, vol. 121, no. 18, pp. 10,555-10,574, 2016.

[21] B. Škerlak, M. Sprenger, and H. Wernli, “A global climatology of stratosphere-troposphere exchange using the ERA-Interim data set from 1979 to 2011," Atmospheric and Physics, vol. 14, no. 2, pp. 913-937, 2014.

[22] A. J. Simmons, P. Poli, D. P. Dee et al., "Estimating lowfrequency variability and trends in atmospheric temperature using ERA-Interim," Quarterly Journal of the Royal Meteorological Society, vol. 140, no. 679, pp. 329-353, 2014.

[23] M. Möller, R. Finkelnburg, and M. Braun, "Climatic mass balance of the ice cap Vestfonna, Svalbard: a spatially distributed assessment using ERA-Interim and MODIS data," Journal of Geophysical Research Earth Surface, vol. 116, no. F3, 2011.

[24] J. K. Zhu, "Salt and drought stress signal transduction in plants," Annual Review of Plant Biology, vol. 53, no. 1, pp. 247-273, 2002.

[25] S. B. Duan, Z. L. Li, H. Li et al., "Validation of Collection 6 MODIS land surface temperature product using in situ measurements," Remote Sensing of Environment, vol. 225, pp. 16-29, 2019.

[26] S.-B. Duan, Z.-L. Li, and P. Leng, "A framework for the retrieval of all-weather land surface temperature at a high spatial resolution from polar-orbiting thermal infrared and passive microwave data," Remote Sensing of Environment, vol. 195, pp. 107-117, 2017.

[27] M. J. Hayes, M. D. Svoboda, D. A. Wilhite, and O. V. Vanyarkho, "Monitoring the 1996 drought using the standardized precipitation index," Bulletin of the American Meteorological Society, vol. 80, no. 3, pp. 429-438, 1999.

[28] Rainfall deciles, Climate Summary of South Africa, 2009.

[29] L. Telesca, S. M. Vicente-Serrano, and J. I. López-Moreno, "Power spectral characteristics of drought indices in the Ebro river basin at different temporal scales," Stochastic Environmental Research and Risk Assessment, vol. 27, no. 5, pp. 1155-1170, 2013.

[30] B. Narasimhan and R. Srinivasan, "Development and evaluation of soil moisture deficit index (SMDI) and evapotranspiration deficit index (ETDI) for agricultural drought 
monitoring," Agricultural and Forest Meteorology, vol. 133, no. 1-4, pp. 69-88, 2005.

[31] K. Tankha and R. K. Gupta, "Effect of water deficit and sulphur dioxide on total soluble proteins, nitrate reductase activity and free proline content in sunflower leaves," Biologia Plantarum, vol. 34, no. 3-4, pp. 305-310, 1992.

[32] A. A. V. D. Griend and M. Owe, "On the relationship between thermal emissivity and the normalized difference vegetation index for natural surfaces," International Journal of Remote Sensing, vol. 14, no. 6, pp. 1119-1131, 1993.

[33] S. M. Vicente-Serrano, S. Beguería, and J. I. López-Moreno, "A multiscalar drought index sensitive to global warming: the standardized precipitation evapotranspiration index," Journal of Climate, vol. 23, no. 7, pp. 1696-1718, 2010.

[34] A. Dai, K. E. Trenberth, and T. Qian, "A global dataset of palmer drought severity index for 1870-2002: relationship with soil moisture and effects of surface warming," Journal of Hydrometeorology, vol. 5, no. 6, pp. 1117-1130, 2004.

[35] T. Qian, A. Dai, K. E. Trenberth, and K. W. Oleson, "Simulation of global land surface conditions from 1948 to 2004. Part I: forcing data and evaluations," Journal of Hydrometeorology, vol. 7, no. 5, pp. 953-975, 2006.

[36] V. K. Lohani and G. V. Loganathan, "An early warning system for drought management using the Palmer drought index," Journal of the American Water Resources Association, vol. 33, no. 6, pp. 1375-1386, 2010.

[37] R. Modarres, "Streamflow drought time series forecasting," Stochastic Environmental Research and Risk Assessment, vol. 21, no. 3, pp. 223-233, 2007.

[38] M. Yun, Z. Wu, H. Hai, G. Lu, H. Xu, and Q. Lin, "Spatiotemporal analysis of drought in a typical plain region based on the soil moisture anomaly percentage index," Science of the Total Environment, vol. 576, pp. 752-765, 2017.

[39] X. H. Xu, Z. Q. Lv, X. Y. Zhou, and N. Jiang, "Drought prediction and sustainable development of the ecological environment," Environmental Science and Pollution Research, vol. 24, no. 35, pp. 26974-26982, 2017.

[40] M. Sarfraz, M. Z. Hussain, and A. Nisar, "Positive data modeling using spline function," Applied Mathematics and Computation, vol. 216, no. 7, pp. 2036-2049, 2010.

[41] F. F. Zhao, Z. X. Xu, J. X. Huang, and J. Y. Li, "Monotonic trend and abrupt changes for major climate variables in the headwater catchment of the Yellow River basin," Hydrological Processes, vol. 22, no. 23, pp. 4587-4599, 2008.

[42] S. C. Babu and G. B. Mthindi, "Developing decentralized capacity for disaster prevention: lessons from food security and nutrition monitoring in Malawi," Disasters, vol. 19, no. 2, pp. 127-139, 1995.

[43] R. Ü. N. Geiger, "Köppen-geiger/Klima der Erde. (wandkarte 1:16 Mill.)," Klett-Perthes, Gotha, Germany, 1965.

[44] G. V. D. Schrier, J. Barichivich, K. R. Briffa, and P. D. Jones, "A scPDSI-based global data set of dry and wet spells for 1901-2009," Journal of Geophysical Research: Atmospheres, vol. 118, no. 10, pp. 4025-4048, 2013.

[45] J. Verbesselt, R. Hyndman, G. Newnham, and D. Culvenor, "Detecting trend and seasonal changes in satellite image time series," Remote Sensing of Environment, vol. 114, no. 1, pp. 106-115, 2010.

[46] M. C. Peel, B. L. Finlayson, and T. A. Mcmahon, "Updated world map of the Köppen-Geiger climate classification," Hydrology and Earth System Sciences, vol. 11, no. 5, pp. 1633-1644, 2007.
[47] T. Hengl, J. M. D. Jesus, G. B. M. Heuvelink et al., "SoilGrids250m: global gridded soil information based on machine learning," PLoS One, vol. 12, no. 2, Article ID e0169748, 2017.

[48] T. Hengl, J. M. D. Jesus, R. A. Macmillan, N. H. Batjes, and M. R. Gonzalez, "SoilGrids1km-global soil information based on automated mapping," PLoS One, vol. 9, no. 8, Article ID e105992, 2014.

[49] S. Wei, T. Hengl, J. M. D. Jesus, Y. Hua, and Y. Dai, "Mapping the global depth to bedrock for land surface modeling," Journal of Advances in Modeling Earth Systems, vol. 9, no. 1, pp. 65-88, 2017.

[50] N. Wells, S. Goddard, and M. J. Hayes, "A self-calibrating palmer drought severity index," Journal of Climate, vol. 17, no. 12, pp. 2335-2351, 2004.

[51] J. Verbesselt, R. Hyndman, A. Zeileis, and D. Culvenor, "Phenological change detection while accounting for abrupt and gradual trends in satellite image time series," Remote Sensing of Environment, vol. 114, no. 12, pp. 2970-2980, 2010.

[52] J. Verbesselt, A. Zeileis, and M. Herold, "Near real-time disturbance detection using satellite image time series," $R e$ mote Sensing of Environment, vol. 123, pp. 98-108, 2012. 

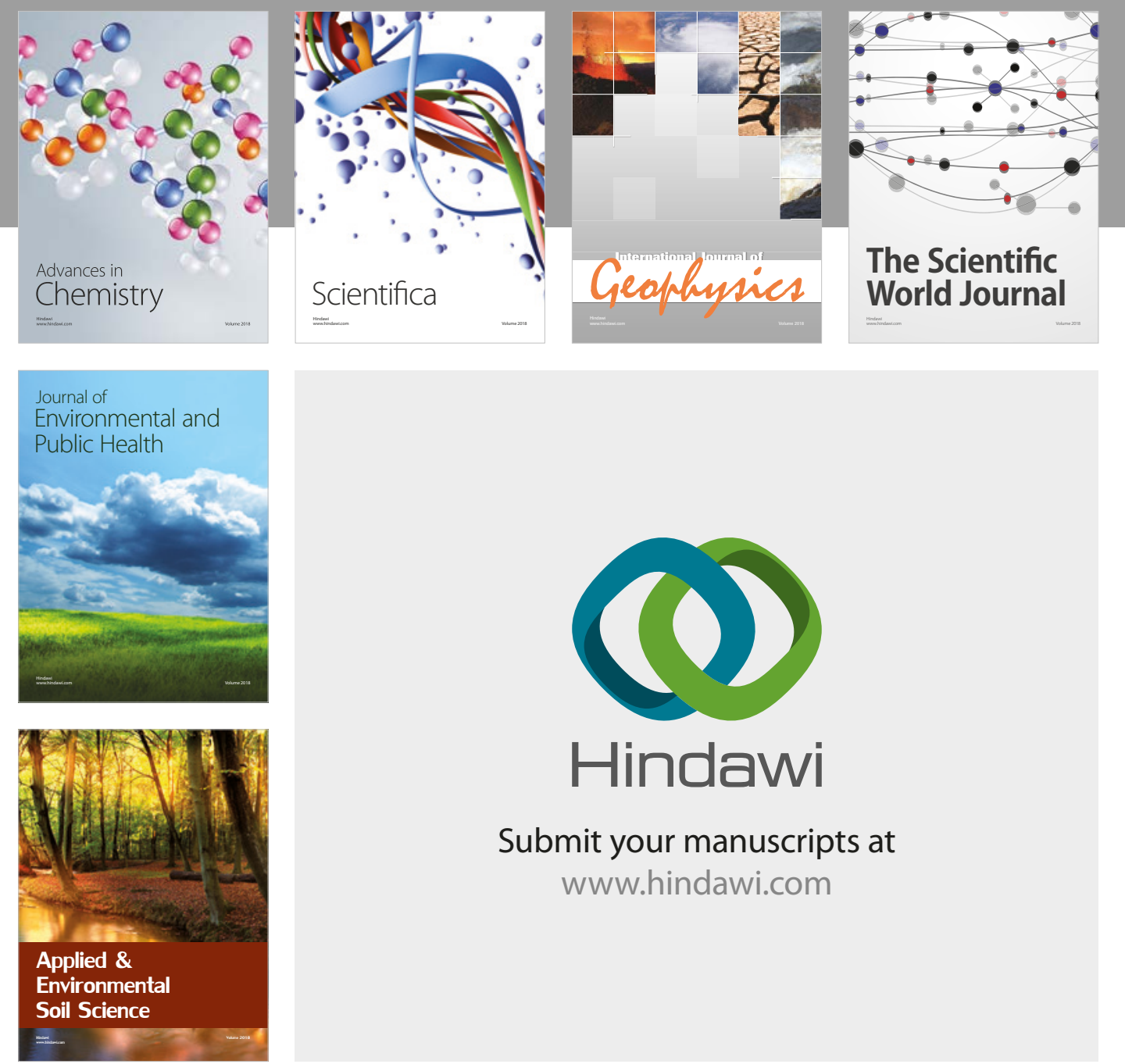

The Scientific

\section{World Journal}
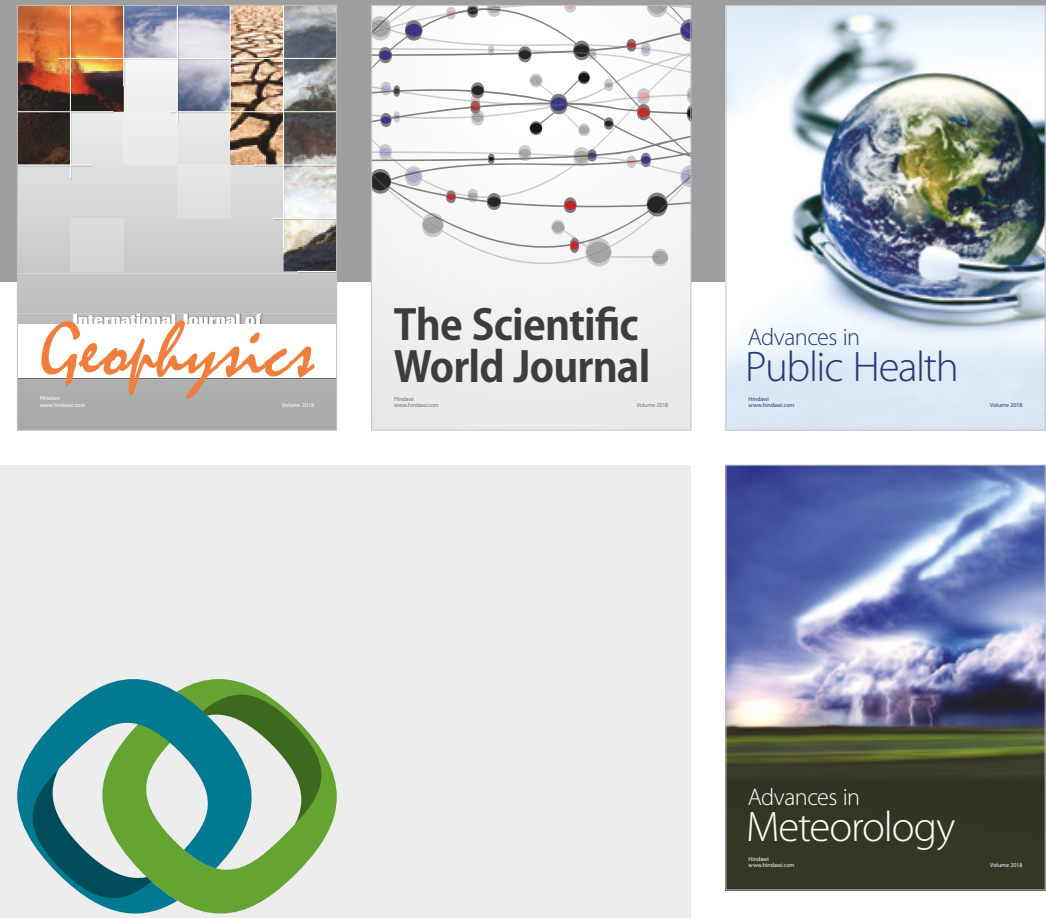

Advan

Public Health

\section{Hindawi}

Submit your manuscripts at

www.hindawi.com
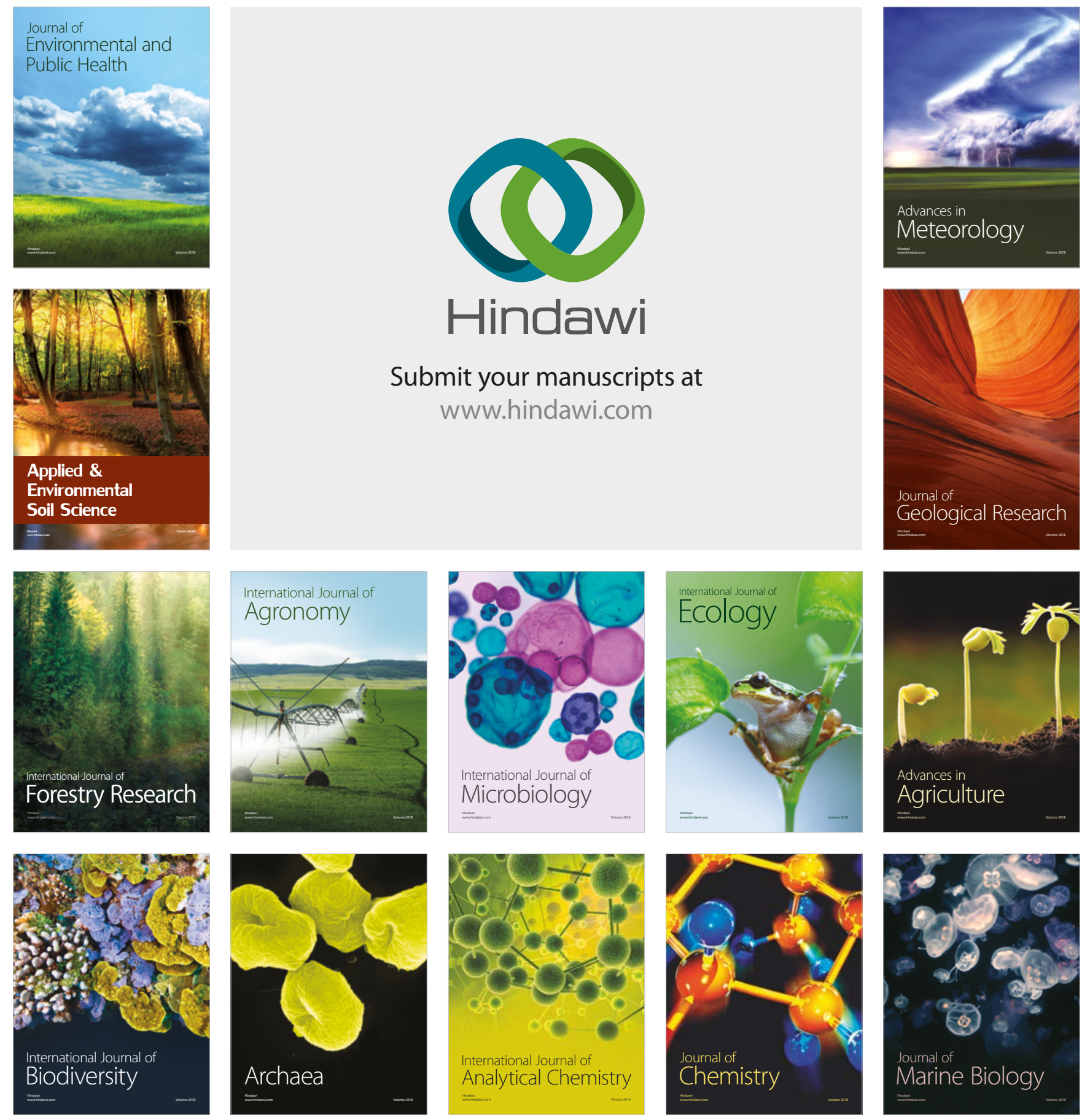